\title{
Korean Alcohol Guidelines for Moderate Drinking Based on Facial Flushing
}

\author{
Sami Lee', Jong-Sung Kim ${ }^{1 *}$, Jin-Gyu Jung', Mi-Kyeong $\mathrm{Oh}^{2}$, Tae-Heum Chung ${ }^{3}$, Jihan Kim \\ 'Department of Family Medicine, Research Institute for Medical Science, Chungnam National University College of Medicine, Daejeon, Korea \\ ${ }^{2}$ Department of Family Medicine, Gangneung Asan Hospital, University of Ulsan College of Medicine, Gangneung, Korea \\ ${ }^{3}$ Department of Family Medicine, Ulsan University Hospital, University of Ulsan College of Medicine, Ulsan, Korea
}

This study investigated advantages and potential risks associated with drinking alcohol in Koreans based on the alcohol flush reaction. Our investigation reviewed published studies and examined moderate-drinking levels for Koreans based on modified National Institute on Alcohol Abuse and Alcoholism guidelines. Fourteen articles out of a total 198 publications were searched using PubMed, EMBASE, KoreaMed, and RISS (Research Information Sharing Service) databases and selected for review. Individuals without alcohol flush reaction (non-flushers) exhibited lower risks associated with insulin resistance, metabolic syndrome, and hyperhomocysteinemia and their 10-year cardiovascular disease risk when alcohol consumption was $\leq 8$ drinks/wk. Conversely, risks associated with insulin resistance, metabolic syndrome, high blood pressure, prediabetes or type-2 diabetes, and high intraocular pressure and increases in carbohydrate-deficient transferrin, gamma glutamyl transferase, and blood glucose levels were present when $>8$ drinks were consumed. For individuals with flushing reaction (flushers), advantages were reported in relation to risks of hyperhomocysteinemia when alcohol consumption was $\leq 4$ drinks/wk, whereas consumption of $>4$ drinks/wk increased the risk of insulin resistance, metabolic syndrome, high blood pressure, pre-diabetes or type-2 diabetes, high-risk colorectal adenoma, and high intraocular pressure and increased carbohydrate-deficient transferrin, gamma glutamyl transferase, and blood glucose levels. The moderate drinking level for Koreans is $\leq 8$ drinks/wk for men aged $\leq 65$ years and $\leq 4$ drinks/wk for men aged over 65 . For women, these limits should be half of those for men. Furthermore, individuals with flushing reaction should maintain an alcohol consumption level half of that for non-flushers.

Keywords: Korean; Alcohol Drinking; Flushing; Guideline

Received: June 17, 2019, Revised: June 27, 2019, Accepted: July 1, 2019

${ }^{*}$ Corresponding Author: Jong-Sung Kim https://orcid.org/0000-0001-5945-0784

Tel: +82-42-280-7548, Fax: +82-42-280-7879, E-mail: josephkim@cnu.ac.kr 


\section{INTRODUCTION}

Korea has a high rate of alcohol consumption. According to the 'global status report on alcohol and health 2014' published by the World Health Organization, ${ }^{1)}$ annual alcohol consumption per capita in Korea is $12.3 \mathrm{~L}$, which is the 15th highest rate globally. Additionally, when considering drinkers only, the annual alcohol consumption per person is even higher, at $27.5 \mathrm{~L}$.

According to the Survey of Mental Disorders in Korea in 2016, ${ }^{2)}$ the lifetime prevalence of alcohol use disorder (AUD) in people aged 1864 years was $12.2 \%$ in 2016 ( $18.1 \%$ for men and $6.4 \%$ for women). While this trend has decreased over time, with rates of $15.9 \%$ in 2001 , $16.2 \%$ in 2006, and $14.0 \%$ in 2011, the prevalence of AUD remains high.

AUD is a condition in which a person continues to consume alcohol despite encountering difficulties in daily life due to their alcohol use. AUD not only has adverse effects on health, but also results in significant social and economic burdens for the individual.

Even in the absence of AUD, drinkers who engage in heavy (weekly average consumption levels exceeding the standard guidelines for moderate drinking) or binge (maximum consumption levels per drinking session exceeding the standards for moderate drinking) drinking have an increased risk for a number of different diseases, which can result in significant socioeconomic problems.

Korean society has a tolerant attitude towards alcohol consumption. This permissive approach has led to alcohol-related problems among some, and, in many cases, these individuals are unaware of their drinking problem. Individuals with alcohol-related problems require treatment, and those who engage in at-risk drinking should make attempts to maintain a moderate drinking level. However, in Korean society many people are unaware of moderate drinking standards and at-risk drinking behavior.

In 2005, the National Institute on Alcohol Abuse and Alcoholism $(\text { NIAAA })^{3)}$ in the United States recommended that doctors confirm whether patients who drink alcohol exhibit at-risk drinking behaviors, defined as heavy or binge drinking. If at-risk drinking was detected, patients were to be further evaluated as to whether they exhibited atrisk drinking or AUD.

The NIAAA has suggested asking three questions related to drinking habits: (1) the average number of drinking sessions per week, (2) the average amount of alcohol consumed at each drinking session, and (3) the maximum amount of alcohol consumed per session. By gathering this information, doctors are able to estimate a person's average weekly alcohol consumption and the maximum level of drinking per session.

To evaluate the amount of alcohol consumed, a standard drink unit is used. The NIAAA defines $14 \mathrm{~g}$ of alcohol as one standard drink unit, which equates to $1.5 \mathrm{oz}$ (approximately $45 \mathrm{~mL}$ ) of $40 \%$ (80 proof) liquor, $5 \mathrm{oz}$ (approximately $150 \mathrm{~mL}$ ) of wine, or $12 \mathrm{oz}$ (approximately $350 \mathrm{~mL}$ ) of beer. These amounts correspond to one glass of liquor or wine, one can or small bottle of beer, and $500 \mathrm{~mL}$ of draft beer would correspond to 1.3 drink units. For traditional Korean drinks, one stan- dard drink unit corresponds to one bowl (approximately $300 \mathrm{~mL}$ ) of Korean rice beer (Makgeoli) or a quarter bottle (approximately $90 \mathrm{~mL}$ ) of $20 \%$ Korean liquor (Soju). ${ }^{4)}$ For other drink types, the standard drinking unit can be calculated using the following formula: drink volume $(\mathrm{mL}) \times$ alcoholic strength by volume $(\%) \times$ specific gravity of alcohol (0.79)=amount of alcohol contained in one drink $(\mathrm{g}){ }^{5}{ }^{5}$

The NIAAA currently defines the maximum drinking limit for moderate drinking (taking $14 \mathrm{~g}$ of alcohol as one standard drink unit) as follows: (1) a maximum of 14 drinks/wk for healthy men aged $\leq 65$ years (but no more than 7 units for healthy women and men aged over 65) and (2) a maximum of 4 drinks/d for healthy men aged $\geq 65$ years (but no more than 3 drinks for healthy women and men aged over 65). In case of women, distinctions are not made on the basis of the age of 65 years.

Koreans are, on average, smaller in physical size than their counterparts in the Western countries, and the inactive form of aldehyde dehydrogenase (ALDH) 2 enzyme is more common in them. ${ }^{6,7)}$ Alcohol is converted into acetaldehyde in the liver by alcohol dehydrogenase $(\mathrm{ADH})$ and broken down into acetate by ALDH in the cytoplasm. Many Asians, including Koreans, have the inactive form of ALDH, which inhibits the breakdown of acetaldehyde. ${ }^{6,7)}$ Therefore, when people with the inactive form of ALDH consume alcohol, acetaldehyde (a toxic substance) accumulates in the body, leading to a characteristic flush. ${ }^{8,9)}$ Therefore, people who exhibit flushing after alcohol consumption are considered to have lower alcohol metabolic capabilities. ${ }^{10,11)}$ Up to $50 \%$ of Asians, including Koreans, have the ALDH 2 gene mutation that causes the facial flushing response. Therefore, it may be inappropriate to apply the current NIAAA recommended alcohol levels to Koreans.

The present study investigated the advantages and risks associated with drinking alcohol in Koreans based on the facial flushing response through a review of previously published studies. We further suggest appropriate moderate-drinking levels for Koreans based on a modification of the NIAAA guidelines.

\section{METHODS}

\section{Data Sources and Search Strategy}

A web-based, electronic database was used for the literature search. PubMed and EMBASE were searched using the keywords 'Korea' or 'Korean' and 'alcohol' or 'alcohol drinking' and 'flushing. For Korean publications, we conducted a search on KoreaMed and the Research Information Sharing Service (RISS). The keywords 'Korea' or 'Korean' and 'alcohol' or 'alcohol drinking' and 'flushing' were used for KoreaMed and 'alcohol' or 'alcohol drinking' and 'flushing' were used for the RISS. Two researchers participating in the study independently conducted the searches. A manual search for reviews in the references of the identified publications was also conducted. No limitations were placed on the language or year of publication, and articles published up to May 20, 2019, were considered. Data were selected through discussion, and a consensus was reached through discussion if disagree- 
ments occurred.

\section{Inclusion Criteria}

We selected papers that met all four of the following criteria: (1) participants were categorized into non-drinkers, flushers, and non-flushers in relation to their alcohol consumption; (2) research participants were Korean; (3) the standard drink unit of $14 \mathrm{~g}$ was used; and (4) an alcohol intake threshold relating to risks or advantages to health indices was provided.

\section{Study Selection and Data Extraction}

A total of 232 publications were searched, including 121 from PubMed, 60 from EMBASE, 28 from the RISS, and 23 from KoreaMed. Two publications were added through a manual search, resulting in a total of 234 publications. We excluded duplicates identified both manually and through the publication management program EndNote X9 (Clarivate Analytics, Philadelphia, PA, USA), resulting in a total of 198 publications. Two researchers reviewed the titles and abstracts to reach a decision regarding the inclusion of the publications. If difficulties arose when determining the appropriateness of an article based on the abstract, the full text was checked. One hundred and eighty publications did not meet inclusion criteria 1, 2, and 3 and were excluded. The remaining 18 publications were reviewed and four publications were found that did not meet inclusion criterion 4 and were excluded. Fourteen papers were ultimately selected for inclusion in the review (Figure 1).

Initial data extraction was accomplished by one researcher who completed the basic template, which was then confirmed through a discussion amongst the authors. Extracted data included information on health-related indices, research participants, and the alcohol consumption threshold indicating either advantages or risks associated with each health-related index among flushers and non-flushers (Tables 1,2). Two review authors independently extracted data, and one author reviewed the publications to verify the extracted contents.

\section{RESULTS}

\section{Advantages of Alcohol Consumption in Korean Adults}

\section{1) Non-flushers}

In a study by Jung et al., ${ }^{12)}$ the risk of insulin resistance was significantly lower among 624 male non-flushers than non-drinkers when the average weekly alcohol quantity was $\leq 4$ drinks in non-flushers, after adjusting for age, exercise, smoking, body mass index (BMI), waist circumference, blood pressure, high-density lipoprotein cholesterol (HDL-C) levels, and triglyceride levels (80 non-drinkers, 238 flushers, and 306 non-flushers) and without underlying diseases including cardiovascular disease and diabetes (odds ratio [OR], 0.3; 95\% confidence interval [CI], 0.11 to 0.86 ).

According to another study by Jung et al., ${ }^{13)}$ the risk of metabolic syndrome was decreased among non-flushers who consumed $\leq 4$ drinks/wk after adjusting for age, BMI, exercise, and smoking in a population of 1,823 Korean men (305 non-drinkers, 540 flushers, and 978 non-flushers) without high blood pressure, diabetes, or high cholesterol levels (OR, 0.59; 95\% CI, 0.33 to 1.06).

In a study by Suh et al. ${ }^{14)}$ examining 1,817 Korean men (283 non-
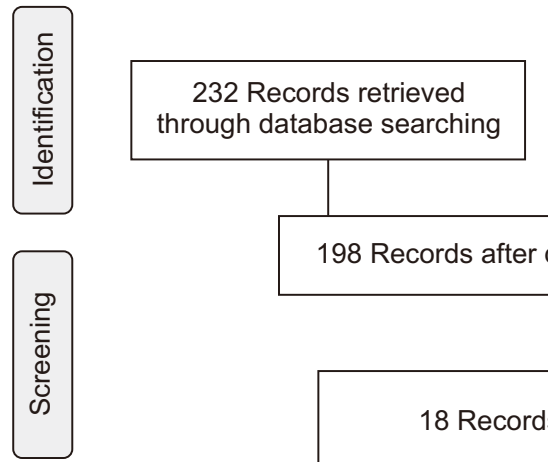

2 Additional records identified through other sources

198 Records after duplicates removed

180 Records excluded on basis of title/abstract

4 Articles excluded due to unmet inclusion criteria 
Table 1. Drinking levels that are advantageous for health-related indices in Korean adults

\begin{tabular}{|c|c|c|c|c|c|}
\hline \multirow{2}{*}{ Index } & \multirow{2}{*}{ No. of participants } & \multirow{2}{*}{ Gender } & \multicolumn{2}{|c|}{ Level of drinking (drinks*/wk) } & \multirow{2}{*}{ Publication } \\
\hline & & & Non-flushers & Flushers & \\
\hline Decreased insulin resistance risk & 624 & M & $\leq 4$ & NS & Jung et al. ${ }^{12)}(2010)$ \\
\hline Decreased metabolic syndrome risk & 1,823 & M & $\leq 4$ & NS & Jung et al. ${ }^{13)}(2012)$ \\
\hline Decreased 10-year cardiovascular disease risk & 1,817 & M & $\leq 4$ & NS & Suh et al. ${ }^{14)}(2014)$ \\
\hline Decreased hyperhomocysteinemia risk & 948 & M & $<8$ & $<4$ & Kim et al. ${ }^{15)}(2013)$ \\
\hline Decreased risk of low serum HDL-C level & 1,443 & M & $>0$ & $\geq 8$ & Kim et al. ${ }^{16)}(2016)$ \\
\hline Decreased benign prostatic hyperplasia risk & 957 & $\mathrm{M}^{+}$ & NS & $>0$ & Jang et al. ${ }^{17)}(2017)$ \\
\hline
\end{tabular}

M, male; NS, non-significant; HDL-C, high-density lipoprotein cholesterol.

*1 drink=14 g alcohol: 1 can of beer, 1 small bottle of beer, $350 \mathrm{~mL}$ of draft beer, rice beer $300 \mathrm{~mL}$ (1 bowl of rice beer), wine $150 \mathrm{~mL}$ (1 glass of wine), $20 \% \mathrm{Soju} 90 \mathrm{~mL}$ (1/4 bottle), and $45 \mathrm{~mL}$ of $40 \%$ liquor (1 shot glass). ${ }^{\dagger}$ Men in their $50 \mathrm{~s}$.

Table 2. Drinking levels associated with risks for health-related indices in Korean adults

\begin{tabular}{|c|c|c|c|c|c|}
\hline \multirow{2}{*}{ Index } & \multirow{2}{*}{ No. of participants } & \multirow{2}{*}{ Gender } & \multicolumn{2}{|c|}{ Level of drinking (drinks*/wk) } & \multirow{2}{*}{ Publication } \\
\hline & & & Non-flushers & Flushers & \\
\hline Increased insulin resistance risk & 624 & M & $>20$ & $>12$ & Jung et al. ${ }^{12)}(2010)$ \\
\hline Increased metabolic syndrome risk & 1,823 & M & $>16$ & $>4$ & Jung et al. ${ }^{13)}(2012)$ \\
\hline Increased metabolic syndrome risk & 1,344 & $\mathrm{~F}$ & $>4$ & $>0$ & $\operatorname{Seo}^{18)}(2018)$ \\
\hline Elevated CDT level & 374 & M & $>12$ & $>4$ & Kim et al..$^{19)}(2013)$ \\
\hline Elevated GGT level & 374 & M & $>8$ & $>4$ & Kim et al. ${ }^{19)}(2013)$ \\
\hline Elevated GGT level & 797 & M & $\geq 4$ & $>0$ & Yang et al. ${ }^{20)}(2016)$ \\
\hline Increased hypertension risk & 1,763 & M & $>8$ & $>4$ & Jung et al. ${ }^{21)}(2014)$ \\
\hline Increased hyperglycemia risk & 802 & M & $>16$ & $>8$ & $\operatorname{Suh}^{22)}(2014)$ \\
\hline Increased prediabetes or T2DM risk & 1,030 & M & $>8$ & $>4$ & Kim et al. ${ }^{23)}$ (Forthcoming 2019) \\
\hline Increased colorectal adenoma risk & 511 & M & NS & $\geq 8$ & Yang $^{24)}(2016)$ \\
\hline Increased high intraocular-pressure risk & 479 & $\mathrm{M}^{+}$ & $>8$ & $>0$ & Lee et al. ${ }^{25)}$ (Forthcoming) \\
\hline
\end{tabular}

M, male; F, female; CDT, carbohydrate-deficient transferrin; GGT, gamma glutamyl transferase; T2DM, type-2 diabetes mellitus; NS, non-significant.

*1 drink=14 g alcohol: 1 can of beer, 1 small bottle of beer, $350 \mathrm{~mL}$ of draft beer, rice beer $300 \mathrm{~mL}$ (1 bowl of rice beer), wine $150 \mathrm{~mL}$ (1 glass of wine), $20 \% \mathrm{Soju} 90 \mathrm{~mL}$ (1/4 bottle), and $40 \%$ liquor $45 \mathrm{~mL}$ (1 shot glass). ${ }^{\dagger}$ Body mass index $\geq 25 \mathrm{~kg} / \mathrm{m}^{2}$.

drinkers, 662 flushers, and 872 non-flushers), the 10-year cardiovascular disease risk was found to be significantly decreased (OR, 0.51; 95\% CI, 0.37 to 0.71 ) among non-flushers with a weekly alcohol consumption of $\leq 4$ drinks, after adjusting for BMI, diastolic blood pressure, lowdensity lipoprotein cholesterol levels, triglyceride levels, and exercise.

In a study by Kim et al., ${ }^{15)}$ the risk of hyperhomocysteinemia was significantly reduced ( $<4$ drinks: OR, $0.27 ; 95 \%$ CI, 0.10 to $0.74 ; 4-8$ drinks: OR, $0.21 ; 95 \% \mathrm{CI}, 0.06$ to 0.73 ) in non-flushers who consumed $<8$ drinks/wk after adjusting for age, BMI, hypertension, diabetes, smoking, triglyceride levels, HDL-C levels, and gamma glutamyl transpeptidase levels in a total of 948 men (182 non-drinkers, 348 flushers, and 418 non-flushers) and after excluding those with underlying diseases including chronic renal failure, hypothyroidism and cancer, or those taking medications that would have affected homocysteine concentrations.

According to research by Kim et al., ${ }^{16)}$ the risk of low serum HDL-C levels significantly decreased across all drinking level categories $(<4$ drinks: OR, 0.43; 95\% CI, 0.28 to 0.66; 4-8 drinks: OR, 0.41; 95\% CI, 0.22 to 0.77 ; 8-16 drinks: OR, 0.29 ; $95 \% \mathrm{CI}, 0.15$ to 0.54 ; >16 drinks: $\mathrm{OR}, 0.34$; 95\% CI, 0.21 to 0.57 ), after adjusting for age, exercise, smoking, BMI, waist circumference, and a history of hypertension and type-2 diabetes mellitus (T2DM), in a total of 1,443 men (261 non-drinkers, 470 flushers, and 712 non-flushers).

\section{2) Flushers}

In a study by Kim et al., ${ }^{15)}$ the risk of hyperhomocysteinemia was significantly lower (OR, 0.30; 95\% CI, 0.13 to 0.68 ) among flushers than non-drinkers when the flushers consumed $<4$ drinks $/$ wk.

In a study by Kim et al., ${ }^{16)}$ flushers who consumed $\geq 8$ drinks/wk showed a significantly reduced risk of low serum HDL-C levels compared to non-drinkers (8-16 drinks: OR, 0.23 ; $95 \% \mathrm{CI}, 0.10$ to 0.54 ; $\geq 16$ drinks: OR, 0.34; 95\% CI, 0.17 to 0.71 ).

According to research by Jang et al. ${ }^{17)}$ that focused on the relationship between benign prostatic hyperplasia (BPH) and drinking, a comparison of 957 men aged between 40 and 69 years (180 nondrinkers, 389 flushers, and 388 non-flushers), found that the risk of BPH was significantly decreased ( $\leq 4$ drinks: OR, 0.38 ; $95 \% \mathrm{CI}, 0.16$ to 0.86 ; $4-8$ drinks: OR, 0.35 ; $95 \%$ CI, 0.13 to 0.95 ; > 8 drinks: OR, 0.33 ; $95 \%$ CI, 0.13 to 0.84 ) among flushers in their 50 s across all drinking-level categories, after adjusting for age, BMI, smoking, and exercise.

A drinking level considered advantageous in relation to the risk of insulin resistance, metabolic syndrome, or a 10-year risk for cardiovascular disease in flushers was not observed. ${ }^{12-14)}$ 


\section{Risks Associated with Alcohol Intake in Korean Adults}

\section{1) Non-flushers}

In the study by Jung et al., ${ }^{12)}$ non-flushers who consumed $>20$ drinks per week showed a significantly higher risk of insulin resistance than non-drinkers (OR, 3.48; 95\% CI, 1.44 to 8.42 ).

Another study by Jung et al. ${ }^{13)}$ found that the risk of metabolic syndrome was significantly higher among non-flushers with a weekly alcohol consumption of $>16$ drinks (OR, 2.02; 95\% CI, 1.15 to 3.55 ).

According to a study by $\mathrm{Seo}^{18)}$ that investigated the relationship between alcohol consumption and metabolic syndrome according to facial flushing in 1,344 Korean women (602 non-drinkers, 334 flushers, and 408 non-flushers), the risk of metabolic syndrome was significantly increased (OR, 2.20; 95\% CI, 1.07 to 4.52) among non-flushers who had a weekly alcohol consumption of $>4$ drinks, after adjusting for age, BMI, exercise, and menopausal status.

In a study by Kim et al. ${ }^{19)}$ in 2013, the cut-off value for the amount of alcohol to increase the percent carbohydrate-deficient transferrin (CDT\%) and gamma glutamyl transferase (GGT) was approximately 12 drinks/wk (62.2\% sensitivity and $69.6 \%$ specificity) and approximately 8 drinks/wk (71.1\% sensitivity and $66.7 \%$ specificity) in 374 male drinkers (107 flushers and 267 non-flushers).

Yang et al. ${ }^{20)}$ also investigated whether there was a difference in the amount of drinking associated with an abnormal expression of GGT in 797 Korean women aged 20-59 years (356 non-drinkers, 137 flushers, and 304 non-flushers). Compared with non-drinkers, non-flushers had a significantly higher risk of GGT elevation if they had $\geq 4$ drinks/ wk (4-8 drinks: OR, 37.57; 95\% CI, 9.79 to 144.12; $\geq 8$ drinks: OR, 20.35; $95 \%$ CI, 20.35 to 305.14 ) after adjusting for age, smoking, menopausal status, and BMI.

Jung et al. ${ }^{21)}$ also examined the role of the facial flushing response in association with alcohol consumption and hypertension in 1,763 Korean men (288 non-drinkers, 527 flushers, and 948 non-flushers). The risk of hypertension was significantly higher among non-flushers when they consumed $>8$ drinks/wk (OR, 1.61; 95\% CI, 1.15 to 2.27 ) after adjusting for age, BMI, exercise, and smoking status.

In a study by $\mathrm{Suh}^{22)}$ examining the relationship between alcohol consumption and impaired fasting glucose in 802 Korean men aged $<65$ years (128 non-drinkers, 343 flushers, and 331 non-flushers), the risk of hyperglycemia was significantly increased among non-flushers who consumed $>16$ drinks per week (OR, 2.52; 95\% CI, 1.28 to 4.95$)$ after adjusting for age, BMI, smoking, and exercise.

According to research by Kim et al., ${ }^{23)}$ the risk of prediabetes or T2DM was significantly increased among non-flushers if they consumed >8 drinks/wk (OR, 2.08; 95\% CI, 1.32 to 3.26) after adjusting for age, BMI, total cholesterol levels, smoking, exercise, and dietary habits in 1,030 Korean men (158 non-drinkers, 364 flushers, and 508 nonflushers). A stratified analysis based on BMI demonstrated that only the obese group (BMI $\geq 25 \mathrm{~kg} / \mathrm{m}^{2}$ ) of non-flushers exhibited a significantly higher risk of prediabetes or T2DM when their average weekly alcohol consumption was $>4$ drinks (4-8 drinks: OR, 2.72; 95\% CI, 1.39 to 5.30 ; >8 drinks: OR, 2.42; 95\% CI, 1.11 to 5.27 ).

In a study by Yang, ${ }^{24)}$ the odds of high-risk colorectal adenoma was not increased among non-flushers after adjusting for age, BMI, exercise, smoking, aspirin use, hyperlipidemia treatment, and family history of colon cancer in 511 Korean men (88 non-drinkers, 196 flushers, and 227 non-flushers).

In a study by Lee et al. ${ }^{25)}$ that included 479 obese Korean men (75 non-drinkers, 174 flushers, and 230 non-flushers) without glaucoma, abnormal intraocular pressure, or hypertension, the risk of high ocular pressure was significantly higher among non-flushers who consumed >8 drinks/wk (8-16 drinks: OR, 4.84; 95\% CI, 1.14 to 20.61; >16 drinks: OR, 4.08; 95\% CI, 1.02 to 16.26 ) after adjusting for age, smoking, diabetes, thyroid abnormalities, cardiovascular diseases, total cholesterol levels, and ocular surgery history.

\section{2) Flushers}

Jung et al., ${ }^{12)}$ demonstrated that a higher risk of insulin resistance was associated with flushers who consumed $>12$ drinks/wk (12-20 drinks: OR, 4.66; $95 \%$ CI, 1.80 to 12.06 ; $>20$ drinks: OR, 3.51; $95 \% \mathrm{CI}, 1.02$ to 12.06).

In another study by Jung et al., ${ }^{13)}$ the authors found that the risk of metabolic syndrome was significantly higher in flushers with a weekly alcohol consumption of $>4$ drinks (4-16 drinks: OR, 1.93; 95\% CI, 1.04 to 3.58 ; >16 drinks: OR, 2.20; $95 \% \mathrm{CI}, 1.02$ to 4.74 ).

According to Seo ${ }^{18)}$ the risk of metabolic syndrome was significantly increased across all drinking groups in female flushers ( $\leq 2$ drinks: OR, 1.68; $95 \%$ CI, 1.10 to 2.68 ; $2-4$ drinks: OR, 2.48 ; $95 \%$ CI, 1.29 to 4.74 ; >4 drinks: OR, 4.11; 95\% CI, 2.03 to 8.30 ).

In a study by Kim et al., ${ }^{19)}$ increases in CDT\% and GGT were induced in flushers with a weekly alcohol consumption of $>4$ drinks (sensitivity of $77.8 \%$ and $68.0 \%$ and specificity of $70.4 \%$ and $76.8 \%$, respectively).

In another study by Yang et al., ${ }^{20)}$ the risk of increased GGT was significantly higher in flushers across all drinking levels ( $<4$ drinks: OR, 4.12; 95\% CI, 1.60 to 10.59 ; 4-8 drinks: OR, 79.21 ; $95 \%$ CI, 24.03 to 261.03 ; $\geq 8$ drinks: OR, $111.34 ; 95 \% \mathrm{CI}, 30.99$ to 400.08 ).

Jung et al. ${ }^{21)}$ showed that the risk of hypertension was significantly increased in flushers who consumed $>4$ drinks/wk (4-8 drinks: OR, 2.23; $95 \%$ CI, 1.22 to 4.08 ; >8 drinks: OR, 2.35 ; $95 \%$ CI, 1.52 to 3.63 ).

$\mathrm{Suh}^{22)}$ found that the risk of hyperglycemia was significantly increased in flushers with a weekly alcohol consumption of $>8$ drinks (816 drinks: OR, 2.42; 95\% CI, 1.06 to 5.53; >16 drinks: OR, 2.50; 95\% CI, 1.14 to 5.49$)$.

In a study by Kim et al., ${ }^{23)}$ flushers with a weekly alcohol consumption of $>4$ drinks showed an increased risk of prediabetes or T2DM (4-8 drinks: OR, 1.93; 95\% CI, 1.06 to 3.53; >8 drinks: OR, 2.73; 95\% CI, 1.58 to 4.69$)$. Furthermore, when stratified by BMI, normal weight (BMI $<23 \mathrm{~kg} / \mathrm{m}^{2}$ ) and overweight (BMI $\geq 23 \mathrm{~kg} / \mathrm{m}^{2},<25 \mathrm{~kg} / \mathrm{m}^{2}$ ) groups showed an increased risk of prediabetes or T2DM if they consumed $>8$ drinks/wk (normal weight flushers: OR, 3.43; 95\% CI, 1.06 to 11.07; overweight flushers: OR, 4.94; 95\% CI, 1.56 to 15.67). In addition, the obese group (BMI $\geq 25 \mathrm{~kg} / \mathrm{m}^{2}$ ) also had a higher risk for prediabetes or 
T2DM at lower alcohol consumption levels, e.g., $>4$ drinks/wk (4-8 drinks: OR, 2.72; 95\% CI, 1.39 to 5.30; >8 drinks: OR, 2.42; 95\% CI, 1.11 to 5.27).

In the study by Yang, ${ }^{24)}$ flushers consuming $>8$ drinks/wk had higher odds of high-risk colorectal adenoma (OR, 3.34; 95\% CI, 1.08 to 10.34).

Lee et al. ${ }^{25)}$ reported that the risk of high ocular pressure was significantly increased among flushers consuming $<16$ drinks/wk ( $\leq 8$ drinks: OR, 4.49; 95\% CI, 1.05 to 19.25 ; 8-16 drinks: OR, 8.14; $95 \%$ CI, 1.37 to 48.45). However, the increased risk of high ocular pressure was not significant among flushers who consumed $\geq 16$ drinks/wk. However, this result may have been due, according to the authors, to a sample size that was too small to detect statistically significant associations.

\section{CONCLUSION}

In this review, we examined the relationship between alcohol consumption and diseases or health-related indices based on the flushing response. An analysis of Korean publications focused on establishing an alcohol-drinking threshold was conducted to suggest guidelines for moderate-drinking levels in Koreans.

Given that $14 \mathrm{~g}$ of alcohol is defined as one standard drink unit, the NIAAA recommends the consumption of $\leq 14$ drinks/wk for men $(\leq 7$ drinks for women and elderly men over the age of 65 years) as the standard for moderate drinking and for the prevention of heavy drinking. ${ }^{3)}$ As a preventative rationale, the risk of AUD is low, approximately 2 per 100 persons, when men consume $\leq 14$ ( $\leq 7$ for women) drinks/ $\mathrm{wk}^{26)}$ The NIAAA guidelines do not, however, reflect alcohol-related clinical and biological comorbidities in the Korean population. Therefore, this study aimed to modify these guidelines by considering the findings of previous studies within a Korean setting.

In addition, the mutated ALDH2 gene that is commonly found in East Asians increases the level of inactive ALDH2. This leads to the inhibition of the breakdown of acetaldehyde, resulting in its accumulation in the body, which cause reactions such as facial flushing. ${ }^{27)}$ For people with inactive ALDH2, alcohol drinking is accompanied by the flushing response. Therefore, a moderate-drinking level should be determined that is half that for non-flushers.

Furthermore, ADH activity in the gastric mucous membrane of women is half of that of men; as a result, the rate of alcohol metabolism is decreased and a greater amount of alcohol is absorbed, even when their alcohol consumption equals that of men. ${ }^{28)}$ Moreover, the lipid solubility (oil/water partition coefficient) of alcohol is 0.14 , which is seven times higher than moisture. Thus, the absorbed alcohol is primarily distributed throughout the water in the body. As this water level is relatively lower among women, underweight people, and elderly individuals, higher blood alcohol levels are observed among these populations even after taking into account the same amount of alcohol consumption. ${ }^{29)}$ Therefore, the drinking threshold for women should be set to half that for men, as it is currently defined by the NIAAA. However, in contrast to men, no specific drinking threshold has been suggested for women based on age. Considering that the threshold for women is half of that for men, the threshold for elderly women should be set to half that for elderly men. Further studies focusing on drinking among elderly women will be required to support this suggestion.

In our study, significant benefits were observed in regards to the risk of insulin resistance, metabolic syndrome, and hyperhomocysteinemia and a 10-year cardiovascular disease risk when the weekly average alcohol consumption was $\leq 8$ drinks in non-flushers. Furthermore, there were increased risks for insulin resistance, metabolic syndrome, increases in CDT and GGT levels, high blood pressure, high blood glucose levels, prediabetes or T2DM, and high intraocular pressure when $\geq 8$ drinks were consumed. Therefore, a moderate drinking threshold for Korean non-flushers should be adjusted to $\leq 8 \mathrm{drinks} /$ wk.

For flushers, significant benefits were reported in association with the risk of hyperhomocysteinemia when the average weekly alcohol consumption was $\leq 4$ drinks. Consuming $>4$ drinks/wk increased the risk of insulin resistance, metabolic syndrome, increases in CDT and GGT levels, high blood pressure, high blood glucose levels, prediabetes or T2DM, high-risk colorectal adenoma, and high intraocular pressure. Therefore, a moderate drinking threshold for Korean flushers should be adjusted to $\leq 4$ drinks/wk.

The NIAAA in the United States defines binge drinking as the consumption of 4 drinks for men and 3 drinks for women in one drinking session. This is based on the definition for the legal limit of intoxication ( $0.08 \mathrm{~g} / \mathrm{dL}$ in 2 hours), which is reached when men consume 5 drinks and women consume 4 drinks within the specified time frame. ${ }^{26)}$

However, there is a significant difference between the average body weights of Korean and American adults; as a result, there are limitations in directly applying American standards of binge drinking to the Korean population. Furthermore, there is no mention of flushers in this context. According to the National Center for Health Statistics in the United States, ${ }^{30}$ the average weight of the American adult man as of 2015-2016 was $89.7 \mathrm{~kg}$ and that of an adult woman was $77.3 \mathrm{~kg}$. In Korea, according to the 2017 National Health Insurance Statistical Yearbook, ${ }^{31)}$ the average adult Korean man weighs $72.3 \mathrm{~kg}$ and the average Korean woman weighs $57.7 \mathrm{~kg}$. Considering that the average weight of an American man is 1.24 times higher than that of a Korean man, and the weight of an American woman is approximately 1.34 times higher than that of a Korean woman, the standard definition for binge drinking should be set at 3 drinks (3.23 drinks) for Korean men and $>2$ drinks (2.24 drinks) for Korean women. Furthermore, taking into consideration that the moderate-drinking level threshold for flushers is half of that for non-flushers, the standards for binge drinking in men and women with a flushing response should be set a 1.5 drinks and 1 drink, respectively; however, this suggestion should be validated by future research.

This is the first study to focus on the establishment of a moderatedrinking level for individuals with the flushing response in a Korean setting. Our results suggest it may be appropriate to revise the NIAAA recommendations for moderate drinking, as shown in Table 3, such that they reflect the characteristics and physical constitutions of the Korean population. The level of drinking appropriate for Koreans is $\leq 8$ 
Table 3. Suggested moderate-drinking guidelines for Koreans

\begin{tabular}{|c|c|c|c|c|c|c|}
\hline \multirow{3}{*}{ Subjects } & \multicolumn{3}{|c|}{ Weekly drinking thresholds (drinks*) } & \multicolumn{3}{|c|}{ Maximum drinking per session (drinks) } \\
\hline & \multirow{2}{*}{ NIAAA } & \multicolumn{2}{|c|}{ Korean } & \multirow{2}{*}{ NIAAA } & \multicolumn{2}{|c|}{ Korean } \\
\hline & & Non-flushers & Flushers & & Non-flushers & Flushers \\
\hline Men $\leq 65$ y & $\leq 14$ & $\leq 8$ & $\leq 4$ & $\leq 4$ & $\leq 3$ & $\leq 1.5$ \\
\hline Elderly men $>65 \mathrm{y}$, women $\leq 65 \mathrm{y}$ & $\leq 7$ & $\leq 4$ & $\leq 2$ & $\leq 3$ & $\leq 2$ & $\leq 1$ \\
\hline Elderly women $>65$ y & NA & $\leq 2$ & $\leq 1$ & NA & $\leq 1$ & $\leq 0.5$ \\
\hline
\end{tabular}

NIAAA, National Institute on Alcohol Abuse and Alcoholism; NA, not applicable.

${ }^{*} 1$ drink=14 g alcohol: 1 can of beer, 1 small bottle of beer, $350 \mathrm{~mL}$ of draft beer, rice beer $300 \mathrm{~mL}$ (1 bowl of rice beer), wine $150 \mathrm{~mL}$ (1 glass of wine), 20\% Soju $90 \mathrm{~mL}$ (1/4 bottle), and $40 \%$ liquor $45 \mathrm{~mL}$ (1 shot glass).

drinks/wk for men aged up to 65 years and $\leq 4$ drinks/wk for men over 65 years. For women under age 65 years, these limits should be set at $\leq 4$ drinks/wk, and for those over 65 years, these should be set at $\leq 2$ drinks/wk. For those with inactive ALDH accompanied by the facial flushing response, the maintenance of a weekly alcohol consumption level half that of non-flushers is suggested.

\section{CONFLICT OF INTEREST}

No potential conflict of interest relevant to this article was reported.

\section{ACKNOWLEDGMENTS}

This study was submitted by the Alcohol Research Institute, The Korean Academy of Family Medicine.

\section{ORCID}

Sami Lee: https://orcid.org/0000-0003-3653-7734

Jong-Sung Kim: https://orcid.org/0000-0001-5945-0784

Jin-Gyu Jung: https://orcid.org/0000-0003-1400-4187

Mi-Kyeong Oh: https://orcid.org/0000-0003-3602-9588

Tae-Heum Chung: https://orcid.org/0000-0001-7994-6242

Jihan Kim: https://orcid.org/0000-0003-1364-5169

\section{REFERENCES}

1. World Health Organization. Global status report on alcohol and health 2014 [Internet]. Geneva: World Health Organization; 2014 [cited 2019 May 18]. Available from: https://apps.who.int/iris/bitstream/10665/ 112736/1/9789240692763_eng.pdf.

2. Korean Ministry of Health and Welfare. The Survey of Mental Disorders in Korea 2016 with adjustment of sex and age [Internet]. Sejong: Ministry of Health and Welfare; 2017 [cited 2019 May 20]. Available from: http://kosis.kr/search/search.do.

3. National Institute on Alcohol Abuse and Alcoholism. Helping patients who drink too much: a clinician's guide [Internet]. Bethesda (MD): National Institutes of Health Publication; 2007 [cited 2019 May 20]. Available from: http://pubs.niaaa.nih.gov/publications/Practitioner/ CliniciansGuide2005/guide.pdf.

4. Korean Ministry of Health and Welfare, Korean Centers for Disease
Control \& Prevention, the National Health Insurance Service. 2018 Counseling Manual of National Health Screening Program. Cheongju: Korean Centers for Disease Control \& Prevention; 2017.

5. Babor TF, Higgins-Biddle JC, Saunders JB, Monteiro M. AUDIT: the Alcohol Use Disorders Identification Test: guidelines for use in primary care [Internet]. Geneva: World Health Organization; 2001 [cited 2019 May 20]. Available from: http://www.who.int/iris/handle/10665/67205.

6. Agarwal DP, Harada S, Goedde HW. Racial differences in biological sensitivity to ethanol: the role of alcohol dehydrogenase and aldehyde dehydrogenase isozymes. Alcohol Clin Exp Res 1981;5:12-6.

7. Mizoi Y, Tatsuno Y, Adachi J, Kogame M, Fukunaga T, Fujiwara S, et al. Alcohol sensitivity related to polymorphism of alcohol-metabolizing enzymes in Japanese. Pharmacol Biochem Behav 1983;18 Suppl 1: 127-33.

8. Crabb DW. Ethanol oxidizing enzymes: roles in alcohol metabolism and alcoholic liver disease. Prog Liver Dis 1995;13:151-72.

9. Mizoi Y, Ijiri I, Tatsuno Y, Kijima T, Fujiwara S, Adachi J, et al. Relationship between facial flushing and blood acetaldehyde levels after alcohol intake. Pharmacol Biochem Behav 1979;10:303-11.

10. Yokoyama A, Muramatsu T, Ohmori T, Kumagai Y, Higuchi S, Ishii H. Reliability of a flushing questionnaire and the ethanol patch test in screening for inactive aldehyde dehydrogenase-2 and alcohol-related cancer risk. Cancer Epidemiol Biomarkers Prev 1997;6:1105-7.

11. Shin CM, Kim N, Cho SI, Sung J, Lee HJ. Validation of alcohol flushing questionnaires in determining inactive aldehyde dehydrogenase-2 and its clinical implication in alcohol-related diseases. Alcohol Clin Exp Res 2018;42:387-96.

12. Jung JG, Kim JS, Oh MK. The role of the flushing response in the relationship between alcohol consumption and insulin resistance. Alcohol Clin Exp Res 2010;34:1699-704.

13. Jung JG, Kim JS, Yoon SJ, Oh MK. Relationships among alcohol consumption, facial flushing response, and metabolic syndrome in healthy men. Ann Epidemiol 2012;22:480-6.

14. Suh HS, Kim JS, Kim SS, Jung JG, Yoon SJ, Ahn JB. Influence of the flushing response in the relationship between alcohol consumption and cardiovascular disease risk. Korean J Fam Med 2014;35:295-302.

15. Kim EC, Kim JS, Jung JG, Kim SS, Yoon SJ, Ryu JS. Effect of alcohol consumption on risk of hyperhomocysteinemia based on alcohol-related facial flushing response. Korean J Fam Med 2013;34:250-7.

16. Kim KP, Kim JS, Kim SS, Jung JK, Yoon SJ, Wei CJ. Relationship among alcohol consumption, facial flushing response and dyslipidemia in male. Korean J Health Promot 2016;16:153-61.

17. Jang HS, Kim JS, Kim SS, Jung JG, Yoon SJ, Yang H, et al. Relationship 
between alcohol consumption and prostatic hyperplasia according to facial flushing after drinking in Korean men. Korean J Fam Med 2017;38:93-8.

18. Seo YR. Relationship between alcohol consumption and metabolic syndrome according to facial flushing in Korean females [dissertation]. Daejeon: Chungnam National University; 2018.

19. Kim SG, Kim JS, Kim SS, Jung JG, Yun SJ, Kim EC. Relationships between the level of alcohol consumption and abnormality in biomarkers according to facial flushing in Korean male drinkers. Korean J Fam Med 2013;34:123-30.

20. Yang JS, Kim JS, Seo WY, Paik SC. Drinking amount associated with abnormal gamma-glutamyl transpeptidase expression in women. Korean J Fam Med 2016;37:2-6.

21. Jung JG, Kim JS, Kim YS, Oh MK, Yoon SJ. Hypertension associated with alcohol consumption based on the facial flushing reaction to drinking. Alcohol Clin Exp Res 2014;38:1020-5.

22. Suh WY. Facial flushing after drinking as determinant for effect of weekly drinking amount on impaired fasting glucose or type 2 diabetes [master's thesis]. Daejeon: Chungnam National University; 2014.

23. Kim JH, Kim JS, Kim SS, Jung JG, Yoon SJ, Seo YR, et al. Influence of facial flushing on pre- or type 2 diabetes risk according to alcohol consumption in Korean male. Korean J Fam Med. Forthcoming 2019.

24. Yang HJ. Alcohol flushing response magnifies the association of alcohol consumption with colorectal high risk adenoma in Korean men [master's thesis]. Daejeon: Chungnam National University; 2016.

25. Lee SM, Kim JS, Kim SS, Jung JG, Yoon SJ, Seo YR, et al. Relationship between alcohol consumption and ocular pressure according to facial flushing in Korean men with obesity. Korean J Fam Med. Forthcoming.

26. National Institute of Health, National Institute on Alcohol Abuse and Alcoholism. Alcohol facts and statistics [Internet]. Bethesda (MD): National Institutes of Health Publication; 2018 [cited 2019 May 18]. Available from: https://www.niaaa.nih.gov/publications/brochures-andfact-sheets/alcohol-facts-and-statistics.

27. Shibuya A, Yasunami M, Yoshida A. Genotype of alcohol dehydrogenase and aldehyde dehydrogenase loci in Japanese alcohol flushers and nonflushers. Hum Genet 1989;82:14-6.

28. Frezza M, di Padova C, Pozzato G, Terpin M, Baraona E, Lieber CS. High blood alcohol levels in women: the role of decreased gastric alcohol dehydrogenase activity and first-pass metabolism. N Engl J Med 1990;322:95-9.

29. Mumenthaler MS, Taylor JL, O'Hara R, Yesavage JA. Gender differences in moderate drinking effects. Alcohol Res Health 1999;23:55-64.

30. Fryar CD, Kruszon-Moran D, Gu Q, Ogden CL. Mean body weight, height, waist circumference, and body mass index among adults: United States, 1999-2000 through 2015-2016 [Internet]. Hyattsville (MD): National Center for Health Statistics; 2018 [cited 2019 May 18]. Available from: https://www.cdc.gov/nchs/data/nhsr/nhsr122-508. pdf.

31. Korean National Health Insurance Service. The 2017 National Health Insurance statistical yearbook [Internet]. Wonju: Korean National Health Insurance Service; 2018 [cited 2019 May 23]. Available from: http://kosis.kr/statHtml/statHtml.do?orgId=350\&tblId=DT_35007_ N132. 